Received: 29 November 2018 Accepted: 2 July 2019 Published online: 12 July 2019
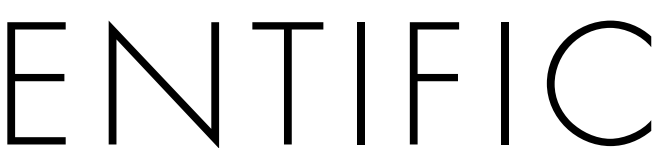

REP

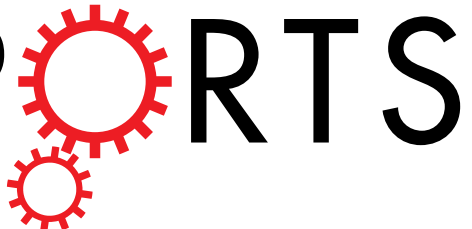

OPEN

\title{
The nutritive value of black soldier fly larvae reared on common organic waste streams in Kenya
}

Marwa Shumo ${ }^{1,2}$, Isaac M. Osuga ${ }^{2,3}$, Fathiya M. Khamis ${ }^{2}$, Chrysantus M. Tanga ${ }^{2}$, Komi K. M. Fiaboe ${ }^{2,4}$, Sevgan Subramanian $\mathbb{D}^{2}$, Sunday Ekesi ${ }^{2}$, Arnold van Huis $\mathbb{D}^{5}$ \& Christian Borgemeister ${ }^{1}$

In Africa, livestock production currently accounts for about $30 \%$ of the gross value of agricultural production. However, production is struggling to keep up with the demands of expanding human populations, the rise in urbanization and the associated shifts in diet habits. High costs of feed prevent the livestock sector from thriving and to meet the rising demand. Insects have been identified as potential alternatives to the conventionally used protein sources in livestock feed due to their rich nutrients content and the fact that they can be reared on organic side streams. Substrates derived from organic by-products are suitable for industrial large-scale production of insect meal. Thus, a holistic comparison of the nutritive value of Black Soldier Fly larvae (BSFL) reared on three different organic substrates, i.e. chicken manure (CM), brewers' spent grain (SG) and kitchen waste (KW), was conducted. BSFL samples reared on every substrate were collected for chemical analysis after the feeding process. Five-hundred (500) neonatal BSFL were placed in $23 \times 15 \mathrm{~cm}$ metallic trays on the respective substrates for a period of $3-4$ weeks at $28 \pm 2^{\circ} \mathrm{C}$ and $65 \pm 5 \%$ relative humidity. The larvae were harvested when the prepupal stage was reached using a $5 \mathrm{~mm}$ mesh size sieve. A sample of $200 \mathrm{grams}$ prepupae was taken from each replicate and pooled for every substrate and then frozen at $-20^{\circ} \mathrm{C}$ for chemical analysis. Samples of BSFL and substrates were analyzed for dry matter (DM), crude protein (CP), ether extracts (EE), ash, acid detergent fibre (ADF), neutral detergent fibre (NDF), amino acids (AA), fatty acids (FA), vitamins, flavonoids, minerals and aflatoxins. The data were then subjected to analysis of variance (ANOVA) using general linear model procedure. BSFL differed in terms of nutrient composition depending on the organic substrates they were reared on. $C P, E E$, minerals, amino acids, ADF and NDF but not vitamins were affected by the different rearing substrates. BSFL fed on different substrates exhibited different accumulation patterns of minerals, with $\mathrm{CM}$ resulting in the largest turnover of minerals. Low concentrations of heavy metals (cadmium and lead) were detected in the BSFL, but no traces of aflatoxins were found. In conclusion, it is possible to take advantage of the readily available organic waste streams in Kenya to produce nutrient-rich BSFL-derived feed.

The global food demand is expected to increase by $70 \%$ by the year 2050 in order to meet the demands of the 9.7 billion people who are forecasted to inhibit the globe by that time ${ }^{1}$. In the recent past already major shifts in diets have happened, favoring more animal-based foods, in particular milk, meat, fish and eggs, and these preferences are expected to increase with time ${ }^{2}$. These changes in dietarian pattern have been accelerated by economic growth, coupled with rapid migration from rural to urban areas, as well an increasing awareness in nutritional needs. By the middle of the current century, cereal and meat production are expected to increase from 2.1 billion and 258 million tons produced per annum between 2005 and 2007 to 3.0 billion and 455 million tons, respectively, raising worldwide concerns regarding the status of food security ${ }^{3}$.

${ }^{1}$ Center for Development Research (ZEF), Department of Ecology and Natural Resources Management, Bonn, 53113, Germany. ${ }^{2}$ International Centre of Insect Physiology and Ecology (icipe), Plant Health Unit, Nairobi, 00100, Kenya. ${ }^{3}$ Jomo Kenyatta University of Agriculture and Technology, School of Natural Resource and Animal Sciences, Department Animal Science, Nairobi, 00200, Kenya. ${ }^{4}$ IPM Department, The International Institute of Tropical Agriculture, BP 2008 (Messa), Yaoundé, Cameroon. ${ }^{5}$ Wageningen University \& Research, Department of Plant Sciences, Laboratory of Entomology, Wageningen, 6700AA, The Netherlands. Correspondence and requests for materials should be addressed to M.S. (email: mshumo@icipe.org) 


\begin{tabular}{|l|l|l|l|l|}
\hline Parameters & CM & KW & SG & p-values \\
\hline DM & $93.3^{\mathrm{a}^{*}} \pm 0.2$ & $92.7^{\mathrm{a}} \pm 0.1$ & $84.6^{\mathrm{b}} \pm 0.5$ & 0.0149 \\
\hline Ash & $20.2^{\mathrm{a}} \pm 0.3$ & $7.2^{\mathrm{b}} \pm 0.3$ & $6.2^{\mathrm{b}} \pm 0.8$ & 0.0005 \\
\hline OM & $86.6^{\mathrm{a}} \pm 0.8$ & $80.4^{\mathrm{b}} \pm 0.4$ & $92.0^{\mathrm{a}} \pm 0.1$ & 0.0015 \\
\hline CP & $15.3^{\mathrm{a}} \pm 0.0$ & $20.0^{\mathrm{b}} \pm 0.5$ & $12.2^{\mathrm{a}} \pm 0.2$ & 0.0008 \\
\hline NDF & $35.5^{\mathrm{a}} \pm 0.8$ & $38.9^{\mathrm{a}} \pm 0.2$ & $49.9^{\mathrm{b}} \pm 1.2$ & 0.0022 \\
\hline ADF & $18.3^{\mathrm{a}} \pm 0.9$ & $25.2^{\mathrm{a}} \pm 1.3$ & $38.6^{\mathrm{b}} \pm 2.5$ & 0.0077 \\
\hline EE & $2.7^{\mathrm{a}} \pm 0.6$ & $7.2^{\mathrm{b}} \pm 0.3$ & $7.2^{\mathrm{b}} \pm 0.2$ & 0.0057 \\
\hline
\end{tabular}

Table 1. Means ( \pm standard error) of proximate composition (in \% dry matter) of three common organic waste streams in Kenya. "Means $(\mathrm{n}=2)$ in the same row followed with different superscripts are significantly different at $\mathrm{p}<0.05$; DM, Dry Matter; OM, Organic Matter; CP, Crude Protein; NDF, Neutral Detergent Fiber; ADF, Acid Detergent Fiber; EE, Ether Extract; CM, Chicken Manure; KW, Kitchen Waste; SG, Spent Grain.

In the developing world, the livestock sector can act as a gateway towards alleviating poverty and enhancing food security ${ }^{4,5}$. Kenyan poultry farming is a significant source of income, especially in rural areas, and contributes to more than quarter of the agricultural Gross Domestic Product (GDP) and accounts for $8 \%$ of the total GDP in Kenya ${ }^{6}$. Yet feed costs make up more than $70 \%$ of the production $\operatorname{costs}^{7-9}$, highlighting the important role economic feeds and their availability could play in successful poultry farming. Due to food-feed competition, feed constituents that are suitable for direct human consumption such as soybean and fish are expensive and collectively increase the costs of feeds ${ }^{8}$. In addition, global catches from the marine fish stocks have dwindled over the years due to overexploitation ${ }^{10}$. This increases the price of fishmeal, which is not only used in feeding livestock but rather is a major source of protein in farmed fish feed ${ }^{11,12}$. Moreover, the intensification of soybean production, especially in the tropics, resulted in land grabbing and deforestation in addition to other negative social and environmental consequences ${ }^{13}$. For the reasons mentioned above, there is an urgent need to replace conventional feed ingredients such as soybean and fish with innovative, economically beneficial and environmentally sustainable ones ${ }^{14}$.

Large-scale rearing of insects is a promising and innovative alternative as several insects' species can feed of various types of organic waste streams ${ }^{15}$. In addition, insects are precious reservoirs of proteins, fatty acids, micronutrients and contain high amounts of energy ${ }^{16-18}$. The latter show a good profile of amino acids in general, and of the most-limiting essential ones like lysine, threonine and methionine, often lacking in plant-based protein sources for non-ruminants ${ }^{19}$.

The Black Soldier Fly (BSF) Hermetia illucens L. (Diptera: Stratiomyidae), the common house fly Musca domestica L. (Diptera: Muscidae) and the yellow mealworm Tenebrio molitor L. (Coleoptera: Tenebrionidae) are among the insect species that have been recognized as promising alternative sources of protein for animal feed ${ }^{20-22}$. The first two naturally occur in animal droppings but also flourish on other organic waste substrates such as coffee bean pulp, vegetables residues, catering waste, municipal organic waste, straw, dried distillers grains with solubles (DDGS), and fish offal ${ }^{15}$, and can add value by reducing organic waste biomass by $50-60 \%$ and turning them into high protein biomass ${ }^{23}$. The yellow mealworm can be reared on vegetables and DDGS ${ }^{24,25}$. The dry weight of Black Soldier Fly larvae (BSFL) contain up to $50 \%$ crude protein(CP), up to $35 \%$ lipids and have an amino acid profile that is similar to that of fishmeal ${ }^{26}$. They are recognized and utilized as alternative sources of protein for feed of poultry, pigs, and several species of fish and shrimp ${ }^{27}$.

The adult fly can typically live for one to two weeks without the need to feed as it appears it can rely on fat body reserve that was acquired during larval stages and can even live longer when fed with water ${ }^{28}$. It does not carry diseases, and actively feeding BSFL secrete an info-chemical that keeps away other species of flies, thereby repelling potential insect pests and disease vectors such as $M$. domestica ${ }^{29}$. The same authors also reported that BSFL significantly influence the reduction of Escherichia coli and Salmonella enterica presence in cow dung while Liu and colleagues ${ }^{30}$ reported the same influence on Escherichia coli in chicken manure. The economic feasibility of the use of insects as feed largely depends on cost effective and readily available organic waste streams, both in the developed and in particular in the developing world. So far, very few studies assessed the holistic nutritional contents of BSFL in terms of quality using experimental diets that were established within the means of the developing world. Unlike rationed diets, organic waste streams in the developing world are heterogeneous in nutritional composition and might be an environment where heavy metals can accumulate. Therefore, the current study sought to perform a comparative holistic analysis of the quality of the nutritional composition of BSFL reared on organic waste streams that are largely and readily available in urban areas of Kenya and the developing world in general. A comparative study that is essential when deciding which organic waste streams are potentially suitable for industrial large-scale BSFL production in Kenya.

\section{Results}

Aflatoxins and proximate composition analysis. LC-Qtof-MS analysis for mycotoxins did not identify any traces of aflatoxin in the BSFL. There was an effect of substrate in all the proximate nutritional parameters (Table 1). The DM content of SG substrate was lower in comparison to the two other rearing substrates $(\mathrm{DF}=2$; $\mathrm{F}=23.23 ; \mathrm{R}^{2}=0.939 ; \mathrm{p}=0.0149$ ) (Table 1 ). The ash content of $\mathrm{CM}$ was higher while the KW and SG ash contents were comparable $\left(\mathrm{DF}=2 ; \mathrm{F}=233.89 ; \mathrm{R}^{2}=0.851 ; \mathrm{p}=0.0005\right)$. Organic matter was lower in $\mathrm{KW}$ while the values obtained from $C M$ and $S G$ were comparable $\left(D F=2 ; F=115.42 ; R^{2}=0.987 ; p=0.0015\right)$. Crude protein content was higher in $\mathrm{KW}$ in comparison to $\mathrm{CM}$ and $\mathrm{SG}\left(\mathrm{DF}=2 ; \mathrm{F}=169.8 ; \mathrm{R}^{2}=0.991 ; \mathrm{p}=0.0008\right)$. Moreover, 


\begin{tabular}{|l|c|l|l|c|}
\hline Parameters & CM fed BSFL & KW fed BSFL & SG fed BSFL & p-values \\
\hline DM & $80.7^{\mathrm{a}^{*}} \pm 1.2$ & $87.7^{\mathrm{b}} \pm 1.0$ & $83.1^{\mathrm{a}} \pm 1.6$ & 0.0050 \\
\hline Ash & $9.3 \pm 1.8$ & $9.6 \pm 1.6$ & $11.6 \pm 0.5$ & 0.4818 \\
\hline OM & $59.8^{\mathrm{a}} \pm 0.4$ & $90.4^{\mathrm{b}} \pm 1.6$ & $88.4^{\mathrm{b}} \pm 0.5$ & $<0.0001$ \\
\hline CP & $41.1^{\mathrm{a}} \pm 0.3$ & $33.0^{\mathrm{b}} \pm 1.0$ & $41.3^{\mathrm{a}} \pm 0.5$ & $<0.0001$ \\
\hline NDF & $21.9^{\mathrm{a}} \pm 0.6$ & $20.4^{\mathrm{a}} \pm 0.6$ & $28.6^{\mathrm{b}} \pm 1.0$ & $<0.0001$ \\
\hline ADF & $12.6^{\mathrm{a}} \pm 0.3$ & $13.2^{\mathrm{a}} \pm 0.1$ & $15.0^{\mathrm{b}} \pm 0.8$ & 0.0101 \\
\hline EE & $30.1^{\mathrm{a}} \pm 0.4$ & $34.3^{\mathrm{b}} \pm 0.4$ & $31^{\mathrm{a}} \pm 0.4$ & $<0.0001$ \\
\hline
\end{tabular}

Table 2. Means ( \pm standard error) of proximate composition (in \% dry matter) of Black Soldier Fly larvae reared on three different rearing substrates. "Means $(n=2)$ in the same row followed with different superscripts are significantly different at $\mathrm{p}<0.05$; DM, Dry Matter; OM, Organic Matter; CP, Crude Protein; NDF, Neutral Detergent Fiber; ADF, Acid Detergent Fiber; EE, Ether Extract; CM, Chicken Manure; KW, Kitchen Waste; SG, Spent Grain; BSFL, Black Soldier Fly larvae.

\begin{tabular}{|l|l|l|l|l|}
\hline Parameters & CM fed BSFL & KW fed BSFL & SG fed BSFL & p-values \\
\hline Phosphorus & $1.0^{\mathrm{a}^{*}} \pm 2.74$ & $2.0^{\mathrm{a}} \pm 0.58$ & $4.8^{\mathrm{b}} \pm 1.37$ & 0.0024 \\
\hline Potassium & $1.7 \pm 5.07$ & $3.6 \pm 1.01$ & $1.3 \pm 0.36$ & 0.0688 \\
\hline Calcium & $1.94 \pm 1.90$ & $1.93 \pm 0.42$ & $3.5 \pm 0.62$ & 0.0528 \\
\hline Magnesium & $1.0^{\mathrm{a}} \pm 0.23$ & $1.3^{\mathrm{a}} \pm 0.14$ & $2.2^{\mathrm{b}} \pm 0.01$ & $<0.0001$ \\
\hline Sodium & $3.3^{\mathrm{a}} \pm 0.05$ & $1.3^{\mathrm{b}} \pm 0.14$ & $0.8^{\mathrm{c}} \pm 1.71$ & $<0.0001$ \\
\hline Iron & $2.1 \pm 1.43$ & $0.9 \pm 0.15$ & $0.4 \pm 0.05$ & 0.3662 \\
\hline Copper & $0.6 \pm 0.20$ & $0.6 \pm 0.19$ & $0.9 \pm 0.31$ & 0.5311 \\
\hline Manganese & $0.3 \pm 0.09$ & $0.2 \pm 0.07$ & $0.3 \pm 0.09$ & 0.5980 \\
\hline Cobalt & $2.5 \pm 0.76$ & $1.1 \pm 0.29$ & $3.2 \pm 1.00$ & 0.1601 \\
\hline Zinc & $0.9 . \pm 2.93$ & $0.5 \pm 1.45$ & $1.0 \pm 3.32$ & 0.2131 \\
\hline
\end{tabular}

Table 3. Means ( \pm standard error) of mineral composition $(\mathrm{g} / \mathrm{kg} \mathrm{DM})$ of three common organic waste streams in Kenya. "Means $(n=2)$ in the same row followed with different superscripts are significantly different at $\mathrm{p}<0.05$; CM, Chicken Manure; KW, Kitchen Waste; SG, Spent Grain; BSFL, Black Soldier Fly larvae.

the values of $\mathrm{NDF}\left(\mathrm{DF}=2 ; \mathrm{F}=87.89 ; \mathrm{R}^{2}=0.983 ; \mathrm{p}=0.0022\right)$ and $\mathrm{ADF}\left(\mathrm{DF}=2 ; \mathrm{F}=36.87 ; \mathrm{R}^{2}=0.983 ; \mathrm{p}=0.0077\right)$ contents in $\mathrm{SG}$ were higher in comparison to the two other rearing substrates. The $\mathrm{EE}$ contents $(\mathrm{DF}=2 ; \mathrm{F}=45.51$; $\mathrm{R} 2=0.968 ; \mathrm{p}=0.0057)$ of the three substrates were rather low $(2.7-7.2 \% \mathrm{DM})$ with CM the lowest.

There was an effect of substrate in all the proximate nutritional parameters of the BSFL except for ash (Table 2). The DM $(\mathrm{DF}=2 ; \mathrm{F}=7.70 ; \mathrm{R} 2=0.507 ; \mathrm{p}=0.0050)$ content of the BSFL was higher in KW fed ones. Crude protein $\left(\mathrm{DF}=2 ; \mathrm{F}=38.48 ; \mathrm{R}^{2}=0.838 ; \mathrm{p}<0.0001\right)$ was high in the $\mathrm{CM}$ and $\mathrm{SG}$ fed larvae and lowest in the KW fed ones, though larvae fed on the latter substrate showed higher crude fat $\left(\mathrm{DF}=2 ; \mathrm{F}=27.65 ; \mathrm{R}^{2}=0.787 ; \mathrm{p}<0.0001\right)$ content than the others. Organic matter $\left(\mathrm{DF}=2 ; \mathrm{F}=306.09 ; \mathrm{R}^{2}=0.976 ; \mathrm{p}<0.0001\right)$ was lower in $\mathrm{CM}$ fed larvae as compared to larvae fed on the two other substrates. Both NDF $(\mathrm{DF}=2 ; \mathrm{F}=32.91 ; \mathrm{R} 2=0.814 ; \mathrm{p}<0.0001)$ and $\mathrm{ADF}(\mathrm{DF}=2 ; \mathrm{F}=6.33 ; \mathrm{R} 2=0.456 ; \mathrm{p}=0.0101)$ contents were higher in SG fed BSF.

There was a high correlation between DM content of the rearing substrates and those of the BSFL for CM $\left(\mathrm{DF}=1 ; \mathrm{F}=34.34 ; \mathrm{R}^{2}=0.851 ; \mathrm{p}=0.0011\right)$ and $\mathrm{KW}\left(\mathrm{DF}=1 ; \mathrm{F}=8.14 ; \mathrm{R}^{2}=0.576 ; \mathrm{p}=0.0290\right)$. However, there was no high correlation between DM content of SG and that of the BSFL $(\mathrm{p}=0.6391)$. Moreover, there was a high correlation between OM content of the rearing substrates and those of the BSFL for CM $(\mathrm{DF}=1 ; \mathrm{F}=1140.79$; $\left.\mathrm{R}^{2}=0.994768 ; \mathrm{p}<0.0001\right), \mathrm{KW}(\mathrm{DF}=1 ; \mathrm{F}=11.99 ; \mathrm{R} 2=0.666481 ; \mathrm{p}=0.0134 ; \mathrm{p}=0.0134)$ and $\mathrm{SG}(\mathrm{DF}=1$; $\left.\mathrm{F}=842.98 ; \mathrm{R}^{2}=0.992 ; \mathrm{p}<0.0001\right)$. Moreover, there was a high correlation between the ash content of $\mathrm{CM}$ and SG and that of the BSFL $\left(D F=1 ; F=10.66 ; R^{2}=0.640 ; p=0.0171\right.$ for $\left.C M\right)\left(D F=1 ; F=23.93 ; R^{2}=0.800 ; p=0.0027\right.$ for SG) while there was no high correlation between the ash content KW and that of the BSFL $(p=0.4196)$. There was a high correlation between $\mathrm{CP}$ content of two of the three rearing substrates and those of the BSFL $\left(\mathrm{R}^{2}=0.983 ; \mathrm{p}<0.0001\right.$ for $\mathrm{CM}, \mathrm{R}^{2}=0.899 ; \mathrm{p}=0.0003$ for $\mathrm{KW}$ and $\mathrm{R}^{2}=0.993 ; \mathrm{p}<0.0001$ for $\left.\mathrm{SG}\right)$. Moreover, $\mathrm{a}$ high correlation was observed between the EE contents of substrates and those of the BSFL $(\mathrm{DF}=1 ; \mathrm{F}=1149.06$; $\mathrm{R}^{2}=0.995 ; \mathrm{p}<0.0001$ for $\mathrm{CM} ; \mathrm{DF}=1 ; \mathrm{F}=1413.99 ; \mathrm{R}^{2}=0.996 ; \mathrm{p}<0.0001$ for $\mathrm{KW}$; and $\mathrm{DF}=1 ; \mathrm{F}=842.98$; $\mathrm{R}^{2}=0.992 ; \mathrm{p}<0.0001$ for $\left.\mathrm{SG}\right)$. There was a high correlation between the NDF content of the rearing substrates and those of the BSFL $\left(\mathrm{DF}=1 ; \mathrm{F}=132.95 ; \mathrm{R}^{2}=0.956819 ; \mathrm{p}<0.0001\right.$ for $\mathrm{CM}$; $\mathrm{DF}=1 ; \mathrm{F}=32.85 ; \mathrm{R}^{2}=0.845562$; $\mathrm{p}=0.0012$ for $\mathrm{KW}$; $\mathrm{DF}=1 ; \mathrm{F}=516.05 ; \mathrm{R}^{2}=0.988507 ; \mathrm{p}<0.0001$ for $\mathrm{SG}$ ). Likewise, there was a high correlation between the ADF contents of the rearing substrates and those of the BSFL for CM $(\mathrm{DF}=1 ; \mathrm{F}=75.40$; $\left.\mathrm{R}^{2}=0.926294 ; \mathrm{p}=0.0001\right), \mathrm{KW}\left(\mathrm{DF}=1 ; \mathrm{F}=332.94 ; \mathrm{R}^{2}=0.982298 ; \mathrm{p}<0.0001\right)$ and $\mathrm{SG}(\mathrm{DF}=1 ; \mathrm{F}=159.60$; $\mathrm{R}^{2}=0.963769 ; \mathrm{p}<0.0001$ for $\left.\mathrm{SG}\right)$.

Mineral composition analysis. The three rearing substrates exhibited different accumulation patterns of minerals (Table 3). Five major minerals, i.e. required in amounts greater $>100 \mathrm{mg} /$ day, were detected. Of those, phosphorus $\left(D F=2 ; F=82.18 ; R^{2}=0.982 ; p=0.0024\right)$, magnesium $\left(D F=2 ; F=63.38 ; R^{2}=0.934 ; p<0.0001\right)$ 


\begin{tabular}{|l|l|l|l|l|}
\hline Parameters & CM fed BSFL & KW fed BSFL & SG fed BSFL & p-values \\
\hline Phosphorus & $3.9 \pm 0.31$ & $4.1 \pm 0.33$ & $4.6 \pm 0.56$ & 0.3446 \\
\hline Potassium & $4.9^{\mathrm{a}^{*}} \pm 0.08$ & $5.7^{\mathrm{b}} \pm 0.04$ & $4.4^{\mathrm{a}} \pm 0.01$ & 0.0005 \\
\hline Calcium & $3.2^{\mathrm{a}} \pm 2.32$ & $2 .^{\mathrm{b}} \pm 1.41$ & $1.7^{\mathrm{c}} \pm 0.51$ & $<0.0001$ \\
\hline Magnesium & $4.0^{\mathrm{a}} \pm 0.34$ & $3.3^{\mathrm{b}} \pm 0.06$ & $3.5^{\mathrm{ab}} \pm 0.09$ & 0.0510 \\
\hline Sodium & $2.4 \pm 0.12$ & $2.0 \pm 0.09$ & $2.6 \pm 0.07$ & 0.1371 \\
\hline Iron & $0.6^{\mathrm{a}} \pm 0.43$ & $2.2^{\mathrm{b}} \pm 0.00$ & $0.3^{\mathrm{a}} \pm 0.00$ & 0.0045 \\
\hline Copper & $0.4^{\mathrm{a}} \pm 0.00$ & $0.2^{\mathrm{a}} \pm 0.00$ & $0.5^{\mathrm{b}} \pm 0.00$ & 0.0006 \\
\hline Manganese & $1.4^{\mathrm{a}} \pm 0.01$ & $0.9^{\mathrm{b}} \pm 0.01$ & $1.1^{\mathrm{a}} \pm 0.01$ & 0.0050 \\
\hline Cobalt & $4.6^{\mathrm{a}} \pm 0.01$ & $2.6^{\mathrm{b}} \pm 0.01$ & $6.5^{\mathrm{c}} \pm 0.02$ & $<0.0001$ \\
\hline Zinc & $0.3 \pm 0.01$ & $0.3 \pm 0.01$ & $0.3 \pm 0.02$ & 0.1831 \\
\hline Ca: P (ratio) & 8.3 & 5.2 & 3.7 & \\
\hline
\end{tabular}

Table 4. Means ( \pm standard error) of mineral composition $(\mathrm{g} / \mathrm{kg} \mathrm{DM})$ of Black Soldier Fly larvae reared on three different rearing substrates. *Means $(n=2)$ in the same row followed with different superscripts are significantly different at $\mathrm{p}<0.05$; CM, Chicken Manure; KW, Kitchen Waste; SG, Spent Grain; BSFL, Black Soldier Fly larvae.

\begin{tabular}{|l|l|l|l|r|}
\hline Parameter & CM fed BSFL & KW fed BSFL & SG fed BSFL & p-values \\
\hline Histidine $^{\dagger}$ & $3.5 \pm \pm 0.3$ & $3.3 \pm 1.6$ & $4.7 \pm 0.5$ & 0.6138 \\
\hline Arginine $^{\dagger}$ & $1.1^{\mathrm{b}^{\mathrm{a}} \pm 1.8}$ & $5.0^{\mathrm{c}} \pm 4.3$ & $2.5^{\mathrm{a}} \pm 2.2$ & $<0.0001$ \\
\hline Lysine $^{\dagger}$ & $4.1 \pm 0.6$ & $4.7 \pm 0.5$ & $4.7 \pm 1.6$ & 0.9296 \\
\hline Glutamine & 0 & $8.1 \pm 0.8$ & 0 & 0.0229 \\
\hline Glutamic acid & 0 & $6.1^{\mathrm{b}} \pm 0.5$ & $3^{\mathrm{a}} \pm 0.2$ & 0.0003 \\
\hline Proline & $1.5^{\mathrm{a}} \pm 1.8$ & $5.1^{\mathrm{b}} \pm 3.5$ & $2.4^{\mathrm{a}} \pm 1.6$ & $<0.0001$ \\
\hline Valine $^{\dagger}$ & $7.2 \pm 0.8$ & $1.2 \pm 2.2$ & $9.3 \pm 0.8$ & 0.0729 \\
\hline Methionine $^{\dagger}$ & $6.1 \pm 0.8$ & $7.9 \pm 0.8$ & $7.4 \pm 0.8$ & 0.2891 \\
\hline Tyrosine & $2.2^{\mathrm{a}} \pm 3.4$ & $4.6^{\mathrm{b}} \pm 3.8$ & $3.0^{\mathrm{a}} \pm 3.5$ & 0.0010 \\
\hline Isoleucine $^{\dagger}$ & $1.6 \pm 1.5$ & $2.6 \pm 4.5$ & $1.8 \pm 1.4$ & 0.7181 \\
\hline Leucine $^{\dagger}$ & $3.0 \pm 5.2$ & $2.9 \pm 5.2$ & $3.7 \pm 4.8$ & 0.3420 \\
\hline Hydro-proline & $7.7^{\mathrm{a}} \pm 4.7$ & $2.5^{\mathrm{b}} \pm 4.5$ & $8.7^{\mathrm{a}} \pm 2.5$ & 0.0298 \\
\hline Phenylalanine $^{\dagger}$ & $1.9^{\mathrm{a}} \pm 2.4$ & $4.6^{\mathrm{b}} \pm 4.7$ & $2.4^{\mathrm{a}} \pm 1.7$ & $<0.0001$ \\
\hline
\end{tabular}

Table 5. Means ( \pm standard error) of amino acids concentration $(\mathrm{mg} / \mathrm{g})$ in Black Soldier Fly larvae reared on three different rearing substrates. ${ }^{*}$ Means $(n=2)$ in the same row followed with different superscripts are significantly different at $\mathrm{p}<0.05$; CM, Chicken Manure; KW, Kitchen Waste; SG, Spent Grain; BSF, Black Soldier Fly; ${ }^{\dagger}$ indicates essential amino acids; BSFL, Black Soldier Fly larvae.

and sodium $\left(\mathrm{DF}=2 ; \mathrm{F}=237.67 ; \mathrm{R}^{2}=0.981 ; \mathrm{p}<0.0001\right)$ significantly differed among the tested BSFL whereas potassium and calcium did not.

BSFL fed on the different substrates exhibited different accumulation patterns of minerals (Table 4). Five major minerals, i.e. required in amounts greater $>100 \mathrm{mg} /$ day, were detected. Of those, potassium $(\mathrm{DF}=2$; $\left.\mathrm{F}=13.41 ; \mathrm{R}^{2}=0.641 ; \mathrm{p}=0.0005\right)$, calcium $\left(\mathrm{DF}=2 ; \mathrm{F}=68.58 ; \mathrm{R}^{2}=0.901 ; \mathrm{p}<0.0001\right)$ and magnesium $(\mathrm{DF}=2$; $\left.\mathrm{F}=3.65 ; \mathrm{R}^{2}=0.328 ; \mathrm{p}=0.051\right)$ significantly differed among the tested BSFL whereas sodium did not.

There was no significant correlation between phosphorus concentrations of the rearing substrates and those of the BSFL ( $\mathrm{p}=0.0354$ for CM; $\mathrm{p}=0.1591$ for KW; and $\mathrm{p}=0.8562$ ). Moreover, there was no significant correlation between potassium concertation of KW rearing substrate and that of the BSFL $(p=0.0153)$. However, there was a high correlation between potassium concentrations of CM and SG rearing substrates and those of the BSFL $\left(\mathrm{DF}=1 ; \mathrm{F}=74.15 ; \mathrm{R}^{2}=0.902618 ; \mathrm{p}<0.0001\right.$ for $\mathrm{CM}$ and $\mathrm{DF}=1 ; \mathrm{F}=84.50 ; \mathrm{R}^{2}=0.913509 ; \mathrm{p}<0.0001$ for $\left.\mathrm{SG}\right)$. For calcium concentrations, there was a high correlation between the concentrations in two of the three rearing substrates tested i.e. CM and SG and those of the BSFL $\left(\mathrm{DF}=1 ; \mathrm{F}=45.77 ; \mathrm{R}^{2}=0.851213 ; \mathrm{p}=0.0001\right.$ for $\mathrm{CM}$, $\mathrm{p}=0.1453$ for $\mathrm{KW}$ and $\mathrm{DF}=1 ; \mathrm{F}=13.07 ; \mathrm{R}^{2}=0.620257 ; \mathrm{p}=0.0068$ for $\mathrm{SG}$ ). Similarly, there was a high correlation between sodium concentrations in the three rearing substrates tested $(\mathrm{DF}=1 ; \mathrm{F}=22.72 ; \mathrm{R} 2=0.739595$; $\mathrm{p}=0.0014$ for $\mathrm{CM}, \mathrm{DF}=1 ; \mathrm{F}=27.13 ; \mathrm{R}^{2}=0.772271 ; \mathrm{p}=0.0008$ for $\mathrm{KW}$ and $\mathrm{DF}=1 ; \mathrm{F}=22.00 ; \mathrm{R}^{2}=0.733312$; $\mathrm{p}=0.0015$ for $\mathrm{SG}$ ). Moreover, there was a high correlation between magnesium concentrations of the three rearing substrates tested and those of the $B S F L\left(D F=1 ; F=74.66 ; R^{2}=0.903213 ; p<0.0001\right.$ for $C M, D F=1$; $\mathrm{F}=262.88 ; \mathrm{R}^{2}=0.970466 ; \mathrm{p}<0.0001$ for $\mathrm{KW} \mathrm{DF}=1 ; \mathrm{F}=762.03 ; \mathrm{R}^{2}=0.989611 ; \mathrm{p}<0.0001$ for $\left.\mathrm{SG}\right)$.

Amino acids composition analysis. Both limiting and non-limiting amino acids were detected in the BSFL, with the choice of substrate significantly affecting their concentrations (Table 5). Yet, in general and for the most limiting amino acids like lysine, methionine, isoleucine and tyrosine no significant substrate effect was 


\begin{tabular}{|l|c|c|c|l|}
\hline Substrate & $\begin{array}{l}\text { CM fed } \\
\text { BSFL }\end{array}$ & $\begin{array}{l}\text { KW fed } \\
\text { BSFL }\end{array}$ & $\begin{array}{l}\text { SG fed } \\
\text { BSFL }\end{array}$ & p-values \\
\hline Luteolin & $8.2 \pm 0.7$ & $9.1 \pm 3.6$ & $9.5 \pm 7.3$ & 0.8752 \\
\hline Apegenin & $8.3^{\mathrm{a} *} \pm 1.1$ & $3.7^{\mathrm{b}} \pm 6.2$ & $8.2^{\mathrm{a}} \pm 1.1$ & 0.0087 \\
\hline Quercetin & $4.6 \pm 1.0$ & $7.9 \pm 3.9$ & $5 \pm 8.2$ & 0.142 \\
\hline Rutin & $8.1 \pm 2.8$ & $4.1 \pm 0.7$ & $5.1 \pm 2.7$ & 0.4538 \\
\hline Kaempferol & $24.7^{\mathrm{a}} \pm 4.6$ & $4.2^{\mathrm{b}} \pm 0.6$ & $17.4^{\mathrm{a}} \pm 6.6$ & 0.0196 \\
\hline
\end{tabular}

Table 6. Means ( \pm standard error) of concentration of flavonoids $(\mathrm{mg} / \mathrm{g})$ in Black Soldier Fly larvae reared on three different rearing substrates. * Means $(n=2)$ in the same row followed with different superscripts are significantly different at $\mathrm{p}<0.05$; CM, Chicken Manure; KW, Kitchen Waste; SG, Spent Grain; BSFL, Black Soldier Fly larvae.

\begin{tabular}{|l|l|l|l|c|l|}
\hline Parameter & $\begin{array}{l}\text { Retention time } \\
(\mathbf{m i n})\end{array}$ & $\begin{array}{l}\text { CM fed } \\
\text { BSFL }\end{array}$ & $\begin{array}{l}\text { KW fed } \\
\text { BSFL }\end{array}$ & SG fed BSFL & p-value \\
\hline Gamma tocopherol & 34.3 & $2.3 \pm 0.2$ & $2.0 \pm 0.2$ & $1.7 \pm 0.1$ & 0.3767 \\
\hline Alpha tocopherol & 34.8 & $7.3 \pm 1.3$ & $9.9 \pm 0.7$ & $17.6 \pm 2.5$ & 0.0713 \\
\hline Provitamin D3 & 35.3 & $1.3 \pm 0.1$ & $1.5 \pm 0.1$ & $1.6 \pm 0.1$ & 0.1399 \\
\hline
\end{tabular}

Table 7. Means ( \pm standard error) of concentrations ( $\mu \mathrm{g} / \mathrm{g}$ ) of vitamins detected in Black Soldier Fly larvae reared on three different rearing substrates. CM, Chicken Manure; KW, Kitchen Waste; SG, Spent Grain; BSFL, Black Soldier Fly larvae.

found. Tryptophan was not detected in the analysis, as it might have been destroyed during the acid hydrolysis process. However, no significant substrate effect was detected in the BSFL for the most important amino acids in animal nutrition, especially for non-ruminants, i.e. methionine $(p=0.2891)$, lysine $(p=0.9296)$, isoleucine $(\mathrm{p}=0.7181)$ and leucine $(\mathrm{p}=0.342)$. KW reared larvae showed significantly higher levels of the non-essential amino acids' proline $\left(\mathrm{DF}=2 ; \mathrm{F}=59.69 ; \mathrm{R}^{2}=0.888 ; \mathrm{p}<0.0001\right)$, hydro-proline $\left(\mathrm{DF}=2 ; \mathrm{F}=4.48 ; \mathrm{R}^{2}=0.374\right.$; $\mathrm{p}=0.0298)$ and tyrosine $\left(\mathrm{DF}=2 ; \mathrm{F}=11.27 ; \mathrm{R}^{2}=0.600 ; \mathrm{p}=0.001\right)$ compared to the larvae fed on the other tested substrates. Glutamine was detected in larvae reared on $\mathrm{KW}$. Glutamic acid $\left(\mathrm{DF}=1 ; \mathrm{F}=28.97 ; \mathrm{R}^{2}=0.743\right.$; $\mathrm{p}=0.0003$ ) was only detected in CM fed BSFL, while KW fed BSFL in most cases showed the highest concentrations of the different amino acids especially in the Phenylalanine $\left(D F=2 ; F=20.07 ; R^{2}=0.727 ; p<0.0001\right)$ content, followed by SG and CM fed BSFL (Table 3).

Flavonoid composition analysis. A total of five flavonoids were detected, with two of them showing a significant substrate effect in their concentrations (Table 6). For both apigenin $\left(\mathrm{DF}=2 ; \mathrm{F}=6.78 ; \mathrm{R}^{2}=0.492\right.$; $\mathrm{p}=0.0087)$ and kaempferol $\left(\mathrm{DF}=2 ; \mathrm{F}=5.40 ; \mathrm{R}^{2}=0.454 ; \mathrm{p}=0.0196\right)$ lower concentrations were recorded in $\mathrm{KW}$ fed BSFL as compared to the other substrates.

Vitamins composition analysis. Three vitamins were detected though the substrate had no significant effects on their concentrations, i.e. Gamma tocopherol $(\mathrm{p}=0.3767)$, Alpha tocopherol $(\mathrm{p}=0.0713)$ and Provitamin D3 ( $\mathrm{p}=0.1399)$ (Table 7).

Fatty acids composition analysis. In total, eleven fatty acids were detected in BSFL (Table 8). Except for linoleic and arachidonic acid, concentrations of fatty acids in SG fed BSFL were always higher, and in some cases even significantly higher than in BSFL fed on the two other substrates (Table 8).

\section{Discussion}

With the rapid rise in urban populations in Kenya and elsewhere in Africa, the problem of waste management increases. Organic waste accounts for more than $78 \%$ of the entire solid waste stream in developing countries ${ }^{31}$, waste in Africa and beyond in the Global South is often dumped in landfills without prior separation of organic waste streams leading to the loss of valuable organic resources that could otherwise be reclaimed ${ }^{32}$. Centralized waste management systems that are widely applied in the developed world require sophisticated infrastructures and are often economically beyond the means of most developing countries. Therefore, there is a need to establish alternative waste management systems that can valorise and recycle organic waste streams yet within the economic means of the developing world. In addition, rapid population growth in Africa and Asia, coupled with urbanization and changes in consumer preferences lead to an increasing demand for food, particularly in terms of animal protein ${ }^{4}$. Because of the ecological and economic shortfalls of common protein sources like fish and soy meal in most animal feed ${ }^{33}$, sustainable and yet nutritionally promising alternative sources of protein are urgently needed to ascertain food security today and in the future.

In this study, we measured the potential of recycling three readily available organic waste streams in Nairobi, Kenya, and arguably also in other megacities in the developing world, and their influence on the nutritional quality of BSFL as a proposed alternative protein source for livestock feed. As the quality of livestock feed is mainly measured in the concentrations of CP present in the feed's dry matter, we conducted a proximate analysis applying the standard methods described by the Association of Official Analytical Chemist ${ }^{34}$ using a nitrogen-to-protein conversion factor of $4.76^{35}$ and obtained significantly high values of $\mathrm{CP}$, surpassing those of soybean meal and 


\begin{tabular}{|l|l|l|l|l|l|}
\hline Parameter & $\begin{array}{l}\text { Retention } \\
\text { Time }(\mathbf{m i n})\end{array}$ & $\begin{array}{l}\text { CM fed } \\
\text { BSFL }\end{array}$ & $\begin{array}{l}\text { KW fed } \\
\text { BSFL }\end{array}$ & SG fed BSFL & p-values \\
\hline Lauric acid & 19.3 & $7.1^{\mathrm{a}^{*}} \pm 1.0$ & $7.4^{\mathrm{a}} \pm 9.0$ & $11.0^{\mathrm{b}} \pm 1.1$ & 0.0098 \\
\hline Myristic acid & 19.6 & $6.8 \pm 0.2$ & $6.9 \pm 11.1$ & $7 \pm 0.3$ & 0.872 \\
\hline Palmitic acid & 19.8 & $6.5 \pm 0.2$ & 0 & $6.1 \pm 0.3$ & 0.3448 \\
\hline Stearic acid & 26.1 & $6.9^{\mathrm{a}} \pm 0.1$ & $5.6^{\mathrm{a}} \pm 0.4$ & $9.6^{\mathrm{b}} \pm 1.6$ & 0.001 \\
\hline Arachidic acid & 26.9 & $6.9^{\mathrm{a}} \pm 0.4$ & $6.1^{\mathrm{a}} \pm 0.5$ & $8.5^{\mathrm{b}} \pm 0.6$ & 0.0061 \\
\hline Palmitoleic acid & 23.05 & $4.4 \pm 5.6$ & $4.2 \pm 3.8$ & $5.1 \pm 3.9$ & 0.3641 \\
\hline Oleic acid & 25.0 & $8.0 \pm 0.2$ & $7.2 \pm 0.1$ & $8 \pm 11.9$ & 0.3348 \\
\hline Linoleic acid & 25.3 & $5.8 \pm 0.3$ & $7.5 \pm 0.1$ & 0 & 0.0766 \\
\hline g-Linolenic acid & 25.0 & $5.6^{\mathrm{a}} \pm 0.1$ & $5.5^{\mathrm{ab}} \pm 0.5$ & $7.4^{\mathrm{b}} \pm 0.4$ & 0.0009 \\
\hline Arachidonic acid & 26.4 & $6.7^{\mathrm{a}} \pm 0.3$ & $5.7^{\mathrm{b}} \pm 0.1$ & $0 \pm 0.1$ & 0.0018 \\
\hline Eicosapentaenoic acid & 26.4 & $5.6^{\mathrm{a}} \pm 0.3$ & $5.9^{\mathrm{a}} \pm 0.1$ & $6.8^{\mathrm{b}} \pm 0.1$ & 0.0106 \\
\hline
\end{tabular}

Table 8. Means ( \pm standard error) of fatty acids concentrations $(\mu \mathrm{g} / \mathrm{g})$ in Black Soldier Fly larvae reared on three different rearing substrates. ${ }^{*}$ Means $(n=2)$ in the same row followed with different superscripts are significantly different at $\mathrm{p}<0.05$; CM, Chicken Manure; KW, Kitchen Waste; SG, Spent Grain; BSFL, Black Soldier Fly larvae.

other commonly used plant proteins in livestock feeds such as canola, cottonseed and sunflower meal ${ }^{36}$. The CP values we obtained in our study ranged between 33 and $41 \%$ which is slightly lower than the range of values (39 to $43 \%$ ) reported by Spranghers and colleagues ${ }^{37}$ for BSFL reared on various organic waste streams. Moreover, Nguyen and colleagues ${ }^{38}$ reported a CP value of $39 \%$ for BSFL reared on fruits and vegetables waste while Sheppard and colleagues ${ }^{23}$ reported $42 \%$ CP for BSFL reared on chicken manure. However, the previously mentioned CP values were obtained using the Kjeldahl standard nitrogen-to-protein conversion factor of 6.25 while the values we reported were obtained using the conversion factor of 4.76 . The total nitrogen content in insects in general and BSF in specific contain nitrogen originating from both protein and non-protein sources such as chitin. Hence, separating non protein from protein nitrogen was necessary in order to obtain accurate crude protein content and to avoid over estimated values that were previously reported using the standard conversion factor ${ }^{35,39}$. When calculated using the standard nitrogen-to-protein conversion factor of 6.25 , the range of CP values we obtained from this study ( 39 to $54 \%$ ) surpassed the range of values previously reported in literature ${ }^{23,37,38}$. Our results were closer to that obtained by Caligiani and colleagues ${ }^{39}$ and Janssen and colleagues ${ }^{35}$ who both used a nitrogen-to-protein conversion factor of 4.76. Similarly, the EE content we found in BSFL was higher than those reported from full fat soybean meal ${ }^{36}$ and commercially available fishmeal ${ }^{40}$. Newton and colleagues ${ }^{41}$ and St-Hilaire and colleagues ${ }^{42}$ reported even higher EE values in BSFL than we found in our study. Previous studies reported an influence of the rearing substrate on the EE content. For instance, Nguyen and colleagues ${ }^{38}$ reported higher EE content for larvae reared on fish and liver in comparison to chicken feed. However, there was no apparent influence of the rearing substrates on the EE content of BSFL in our study.

In addition to $\mathrm{CP}$, other nutritional components of livestock feed can greatly enhance the quality of animal production, including several minerals and vitamins including calcium, magnesium, phosphorus, copper, cobalt and vitamins A or D. For example, calcium and phosphorous play important roles in $\mathrm{x}$ physiological functions of animals including muscle mass reductions, neuro-signaling, enzymatic activity, metabolic reactions, construction of proteins, maintenance of osmotic and acidic- alkaline equilibria, construction of membranes etc. ${ }^{43,44}$. When referring to bone and egg formation in layer hens, calcium in particular plays a crucial role as it contributes to more than $90 \%$ of the mineral matrix in the bones ${ }^{45}$. Therefore, deficiencies in calcium and phosphorus can result in bone loss, growth retardation and abnormal posture ${ }^{45}$. The range of calcium concentrations reported in this study (1.7 to $3.2 \%$ ) was lower than that reported in literature $(2.4 \text { to } 5.8 \%)^{46-48}$. Previous studies already established an influence of the rearing substrate on the mineral content of BSFL. Moreover, Newton and colleagues ${ }^{48}$ reported higher calcium concentration for BSFL reared on poultry manure in comparison to the concentration we obtained from BSFL reared on a similar substrate. Such a variability could be further justified by the fact that the outer layer of the larvae's skin releases a deposit of calcium carbonate $\left(\mathrm{CaCO}_{3}\right)$ which may lead to the high calcium and ash content ${ }^{49,50}$. However, while the BSFL calcium levels we detected varied among the three organic waste streams tested, phosphorus levels remained unaffected in our study. The again, Newton and colleagues ${ }^{41}$ reported higher levels of phosphorus in BSFL reared on poultry manure than those reared on swine manure. This variability could also be attributed to the influence of the rearing substrate on the mineral content of BSFL.

Animal feed needs to contain sufficient quantities of vitamins to facilitate the development of proper and healthy body functions ${ }^{51}$. Vitamins contribute essentially to the development of the immune system in animals while also helping in the digestion of other nutrients for energy production ${ }^{51}$. We did not observe any influence of the rearing substrates on vitamins in the BSFL. Though gamma and alpha tocopherol and provitamin D3 were detected in all BSFL samples in our study, Finke and colleagues ${ }^{46}$ and St-Hillarie and colleagues ${ }^{42}$ reported relatively higher levels of alpha tocopherol and provitamin D3. In addition, they found more vitamins including biotin, folic acid, vitamin A, and niacin in their studies with BSFL.

Amino acids are essential for quality livestock production, especially their ability to break down other proteins and to produce energy ${ }^{52}$. Though the amino acid profile of soymeal is generally of a better quality than that of other plant-based feeds, it is still deficient in lysine, methionine, threonine and valine when compared 
to an animal based protein source ${ }^{52}$. Previous studies established that the amino acid profile of several edible insects including the yellow mealworm, common housefly, and BSF is comparable to that of soybean meal with methionine or methionine and cysteine and sometimes arginine as the most limiting essential amino acids for growing swine and broilers ${ }^{53}$. We could show that BSFL reared on the three tested organic waste streams had a higher quality amino acid profile than the $\mathrm{FAO}^{54}$ standard amino acid profiles reported for soybean and sunflower meal. The BSFL methionine levels in our study even surpassed that of fishmeal reported by $\mathrm{FAO}^{54}$ and corresponded with the recommended range for broiler chickens as per the standards of the National Research Council $(\mathrm{NRC})^{55}$. Similarly, the range of methionine levels (6.4 to 7.9\%) in BSFL detected in our study surpassed those of methionine $(0.7$ to $0.9 \%)$ of BSFL reared on various organic waste streams and previously reported in literature ( $^{49}$. Moreover, we detected higher lysine levels in BSFL than commonly found in soybean and sunflower meals ${ }^{2}$ and ours were only slightly lower than in fish meal ${ }^{2}$. Moreover, lysine levels detected in our study (4.1\%) were higher than the levels previously detected by Arango Gutiérrez and colleagues ${ }^{56}$, viz. $2.1 \%$ for BSFL reared on chicken manure. Thus, rearing BSFL on the three tested organic waste streams resulted in terms of amino acids profile in a high quality protein source that would be in this respect nearly at par with fish meal and clearly surpass many plant-based protein sources in livestock feed.

FAs are usually subdivided into either saturated fatty acids (SFA) or unsaturated fatty acids (USFA). High levels of SFAs in diets such as palmitic and myristic acid are not favorable because they raise the level of low density lipoproteins (LDLs) by suppressing the expression of LDL receptors ${ }^{57,58}$. USFAs are important for human growth, skin protection and can decrease the possibility of thrombosis formation ${ }^{59}$. Insect fat is abundant in USFAs and resembles chicken and fish in their level of unsaturation ${ }^{60}$; yet, FAs profiles considerably vary among different insect species ${ }^{61}$. Such variability may be associated with environmental conditions such as the insect's age, sex or size and its digestion and enzymatic activities ${ }^{62}$. We obtained higher USFA in comparison to SFA contents confirming the high quality of the BSFL FA profile. Like Makkar and colleagues ${ }^{2}$ we observed that the FA profile is influenced by the rearing substrate, with SG in general resulting in higher FA levels than the other two tested organic waste stream materials. BSFL FA profiles were predominantly composed of lauric, oleic and stearic acids. This corresponds to previous studies done by Leong and colleagues ${ }^{63}$ Zheng and colleagues ${ }^{64}$ though their values of lauric acid were relatively high compared to our results. The total amount of USFA in BSFL is close to those in olive, or soya oils ${ }^{65}$. In particular, the concentration of lauric acid in BSFL-derived oil is considerably higher than in those derived from soybean, sunflower, and oil palm ${ }^{66}$. Lauric acid is known to react against lipid enveloped viruses, and many pathogenic bacteria and protozoa ${ }^{67-69}$.

Flavonoids occur naturally in vegetables, fruits and medicinal plants. Flavonoids occur naturally in vegetables, fruits and medicinal plants. They perform significant biological actions by acting as antioxidants, anti-carcinogens, anti-allergens, anti-pathogens and growth promoters in different animal species ${ }^{70}$. Studies on insects like edible stink bugs confirmed the presence of alkaloids, flavonoids and steroids among other bioactive compounds $\mathrm{s}^{71,72}$. Flavonoid rich feed are sometimes associated with pharmacological effects ${ }^{73}$. In our BSFL we found rutin, apeginin and luteolin, belonging to the flavone class, usually associated with fruit skins, red wine, buckwheat, red pepper and tomato $\operatorname{skin}^{74,75}$ and kaemferol and quercetin belonging to the flavonol class that are more prevalent in onion, red wine, olive oil, berries and grapefruits ${ }^{76}$. The presence of these flavonoids in the insects can probably be traced back to the different rearing substrates and were acquired through feeding.

Contrary to previous studies which showed that insects are prone to accumulate toxins or heavy metals ingested through contaminated feed or water (e.g. ${ }^{77}$ ) we did not detect any aflatoxins or other mycotoxins in our BSFL. Mycotoxins are metabolic products of fungi with harmful poisoning effects to animals and humans. Monogastrics like pigs and poultry are highly susceptible to such contaminated feed ${ }^{78}$. Thus, to further promote insect-derived feeds, routine and rigorous testing schemes for toxins and heavy metals, both in the rearing substrates as well in the harvested BSFL, have to be implemented. Purschke and colleagues ${ }^{79}$ reported that BSFL accumulated heavy metals but not mycotoxins when fed with contaminated substrates, though their concentrations in BSFL tissues -apart from $\mathrm{Cd}$ and $\mathrm{Pb}$ - remained below the initial substrate concentrations. Therefore, in order to ensure feed and food safety from farm to fork, screening of both the substrates and the BSFL-derived feeds as for contaminants such as $\mathrm{Cd}$ and $\mathrm{Pb}$ is a necessity. In addition to toxins, microbiological contamination might be a matter of concern when it comes to the utilization of insects in feedstock production. Indeed, insects are often affiliated to various microbes such as bacteria, fungi and viruses which are part of their defense repertoire ${ }^{18,80}$. However, BSF have shown an extreme resistance to various environmental conditions through their ability to reduce and possibly suppress possible bacterial and fungal contaminations aided by chemical and biological agents they produce ${ }^{81,82}$. It is suggested that contact with wild insects and other sources of contamination should be avoided in order for properly maintained insect mass rearing facilities to remain free from pathogenic hazards $s^{80}$. Moreover, the possibility of insects to harbor parasites can be limited and contained through introducing and maintaining environmental conditions that are unfavorable to parasitic existence ${ }^{80}$. Therefore and on the basis of our current knowledge, biological risks associated with insect consumption can be minimized using simple hygienic measures such as appropriate processing methods, i.e. heating or freezing similar to measures that are applied during processing of poultry, pork and fish ${ }^{80}$.

Comparing the nutritional composition and quality of BSFL we found in our study with previous research indicates considerable variability. This might be due to differences in methodological set-up, environmental conditions, rearing substrates, time of harvest, as well as harvesting and processing methods ${ }^{15,16,30,41,42,83,84}$. Yet we found the differences between our results and those by Newton and colleagues ${ }^{41}$ and St-Hilaire and colleagues ${ }^{42}$ puzzling, considering that these authors tested similar organic waste streams and processed and harvested the BSFL more or less the same as we did. Hence, we hypothesize that genetic heterogeneity of BSFs is an additional factor that needs to be considered and should thus be looked at. 


\section{Conclusion}

We could show that commonly available organic waste streams in urban environments of the developing world can be successfully used to produce high quality BSFL that have the potential to substitute other animal- or plant-derived protein sources in commercial livestock feed. Wide-scale application of this approach would greatly reduce the ecological and economic footprint of feed, thereby contributing to more sustainable animal husbandry systems. Moreover, it can provide valuable ecosystem services through the bioconversion of municipal and organic waste streams into biocompost. To achieve this, the next step has to be the development of appropriate and cost-effective BSF mass-rearing technologies. Following the footsteps of Kenya and Uganda where dried insect products were recently approved for use in all animal and fish feed ${ }^{85}$, a regional African insect feed policy aiming to ensure safety of production within adequate hygiene standards should be introduced.

\section{Materials and Methods}

The study was carried in the laboratories of the International Centre for Insect Physiology and Ecology (icipe), in Nairobi, Kenya.

Stock colony. icipe insectarium maintains a population of BSF adults which act as a stock colony. The population of the stock colony was originally collected from the surroundings of icipe in Nairobi and was maintained in the insectarium for 1 year before use in this study. Adult BSF are housed in an outdoors metal framed cage with screen mesh $(1.8 \times 1.8 \times 1.8 \mathrm{~m}$ with $1.5 \mathrm{~mm}$ mesh $)$ with strong access to daylight spectra and temperatures maintained at $28 \pm 5^{\circ} \mathrm{C}$ to encourage mating to occur. The flies are supplied with water to prolong their life. Corrugated cardboard and some SG are placed within the cage to attract adult females for egg laying.

Preparation of substrate and larvae feeding. The tested substrates, i.e. chicken manure (CM), kitchen waste (KW) and brewers' spent grain (SG), were all sourced locally. CM was collected form a broiler poultry farm in the greater Nairobi area and used one week after it was harvested. Though the use of manure in feeding farmed animals including insects is prohibited in the European Union (EU), feeding farmed insects with any type of substrate is not an issue as long as the end product is free of heavy metals, microbial and mycotoxins contaminants ${ }^{85,86}$. KW was a mixture of potato peeling, carrot remaining and peelings, rice and bread debris (contained no meat) collected from a local restaurant in Nairobi. SG was sourced from Tusker House, Kenya Breweries Ltd. in Nairobi after fermentation of barley in the beer production process. The substrates were chosen on the basis of their availability in Nairobi, with a view of their potential future use for large scale industrial BSFL production in Kenya and beyond in Africa. Metallic trays measuring $23 \times 15 \mathrm{~cm}$ were used to contain $1 \mathrm{~kg}$ of the different substrates. Each substrate had six replications placed randomly in a wooden frame in a room. Five-hundred (500) neonatal BSFL were placed carefully on top of the substrate in each of the trays. During the rearing process, the temperature was maintained at $28 \pm 2{ }^{\circ} \mathrm{C}$ and relative humidity (r.h.) at $65 \pm 5 \%$. Distilled water was sprinkled on the substrate to ensure $65-70 \%$ moisture content. All substrates were replenished weekly with fresh ones. After reaching the prepupal stage, the insects were harvested, washed with tap water, oven dried at $60^{\circ} \mathrm{C}$ for 48 hours, crushed using a laboratory blender and then stored for subsequent analyses in a refrigerator at $-20^{\circ} \mathrm{C}$. A sample of the BSFL was collected from each replication, pooled and a $200 \mathrm{~g}$ sample was used for the subsequent analyses.

Chemicals. Aflatoxin B1, B2 G1 and G2, were purchased from Supelco (Bellefonte, Pennsylvania, USA), apigenin $(>99 \%)$, luteolin $(>97 \%)$, rutin hydrate $(>94 \%)$, quercetin dehydrate $(>98 \%)$, octadecanoic acid (>98.5\%), glutamic acid, myristoleic acid, tetradecanoic acid, hexadecanoic acid, (Z)-9-hexadecenoic acid, linoleic acid, (Z)-9-octadecenoic acid, octadecanoic acid, (Z,Z)-9,12-0ctadecadienoic acid, oleic acid, eicosanoic acid and amino acid standard solution (AAS 18) were purchased from Sigma-Aldrich (Chemie GmbH Munich, Germany).

Proximate analysis. Prior to the proximate analysis and after reaching the prepupal stage, the insects were harvested, washed with tap water, oven dried at $60^{\circ} \mathrm{C}$ for 48 hours, crushed using a laboratory blender and then stored for subsequent analyses in a refrigerator at $-20^{\circ} \mathrm{C}$. Then, the BSFL samples were taken for proximate analysis using standard methods of the Association of Official Analytical Chemist ${ }^{34}$. Dry matter was calculated by the weight difference between before and after drying the sample in the oven at $135^{\circ} \mathrm{C}$ for two hours; ash was determined by heating the samples in a muffle furnace set at $600^{\circ} \mathrm{C}$ for three hours while $\mathrm{CP}$ was determined using the Kjeldahl method and a nitrogen-to-protein conversion factor of 4.76 was used in the calculation of $\mathrm{CP}^{35}$. Diethyl ether was used as an extractant in the determination of crude fat using the Velp solvent extractor (SER 148/6). Acid detergent fiber (ADF) and neutral detergent fiber (NDF) were analyzed with a Velp fiber analyzer (FIWE 6) (VELP Scientifica, Usmate Velate, Italy) using reagents described by Van Soest and colleagues ${ }^{87}$. All the analyses were done in duplicates.

Amino acids. The method for protein extraction was adopted from Hamilton and colleagues ${ }^{88}$ and detailed in Musundire and colleagues ${ }^{89}$ Briefly, the BSFL samples were separately snap-frozen in liquid nitrogen and crushed into fine powder. The samples (2 g each) were extracted for 1 hour in ice cold 5 v/w $100 \mathrm{mM} 4$-(2-hydroxyethyl)-1piperazineethanesulfonic acid (HEPES) pH 7.2, $2 \mathrm{mM}$ dithiothreitol (DTT), 2.5\% Polyvinylpyrrolidone (PVP), $0.5 \mathrm{mM}$ Ethylenediaminetetraacetic acid (EDTA), $1 \mathrm{mM}$ benzamidine $0.1 \mathrm{mM}$ phenylmethanesulfonylfluoride (PMSF) in a magnetic stirrer. The samples were filtered through KERLIX ${ }^{\mathrm{TM}}$ Gauze Bandage Rolls Sterile Soft Pouch $5.7 \times 2.7 \mathrm{~cm}$ centrifuged at $8,000 \mathrm{rpm}$ for $30 \mathrm{~min}$ at $4^{\circ} \mathrm{C}$ to remove solid debris. Protein was precipitated between $45 \%$ and $80 \%(\mathrm{NH} 4) 2 \mathrm{SO} 4$ and the pellet recovered by centrifugation at $21,000 \mathrm{rpm}$ for $30 \mathrm{~min}$ at $4{ }^{\circ} \mathrm{C}$. The protein pellets were desalted in $20 \mathrm{mM}$ HEPES-NaOH pH 8 containing 2mMDTT using Sephadex G-25 gel filtration chromatography (PD-10 columns, GE Healthcare, Chicago, USA) to give $80.2 \mathrm{mg}$ and $77.9 \mathrm{mg}$ of proteins from processed and unprocessed insect samples, respectively. Ten (10) $\mathrm{mg}$ from each of the samples 
were separately transferred into a $5 \mathrm{ml}$ micro-reaction vial into which $2 \mathrm{ml}$ of $6 \mathrm{~N} \mathrm{HCl}$ were added and closed after careful introduction of nitrogen gas. The samples were hydrolyzed for 24 hours at $110^{\circ} \mathrm{C}$. For tryptophan analysis, $10 \mathrm{mg}$ from each of the samples were separately transferred into a $5 \mathrm{ml}$ micro-reaction vial into which $2 \mathrm{ml}$ of $6 \mathrm{~N}$ $\mathrm{NaOH}$ were added and then capped after careful introduction of nitrogen gas. The samples were hydrolyzed for 24 hours at $110^{\circ} \mathrm{C}$. After the hydrolysis, the mixtures were evaporated to dryness under vacuum. The hydrolysates were reconstituted in $1 \mathrm{ml}$ 90:10 water: acetonitrile, vortexed for $30 \mathrm{~s}$, sonicated for $30 \mathrm{~min}$, and then centrifuged at 14,000 rpm and the supernatant analyzed using a liquid chromatography quadrupole time-of-flight mass spectrometry (LC-Qtof-MS) (Waters Corporation, Milford, USA). The analysis was replicated three times.

Mineral analysis. After drying the prepupae and pre-experiment substrates, they were crushed using a laboratory blender and then ashed and digested in $6 \mathrm{~N} \mathrm{HCl}$. An Atomic Absorption Spectrophotometer (Model AA6300, Shimadu, Japan) was used to analyze the following minerals: phosphorus, potassium, calcium, magnesium, sodium, iron, copper, manganese, cobalt and zinc.

Analysis of mycotoxins. Samples of BSFL were analyzed for mycotoxins according to methods described by Cheng and Cappozzo ${ }^{90}$ and Musundire and colleagues ${ }^{89}$. Ten (10) $\mathrm{g}$ of every sample were snap frozen in liquid nitrogen, crushed into fine powder and extracted in $40 \mathrm{~mL}$ acetonitrile-water $(86: 16, \mathrm{v} / \mathrm{v})$ for 30 min while sonicating. Each mixture was allowed to settle for $30 \mathrm{~min}$ and then $6 \mathrm{~mL}$ of each sample was filtered through a solid phase extraction cartridge Multisep ${ }^{\circledR} 228$ AflaPat multifunctional columns (Roer Labs, USA). An aliquot $(4 \mathrm{ml})$ of each cleaned extract was evaporated to dryness in a stream of nitrogen gas. The dried samples were re-dissolved in $400 \mu \mathrm{L}$ methanol-water $(20: 80, \mathrm{v} / \mathrm{v})$, vortexed for $1 \mathrm{~min}$ and then centrifuged at $14,000 \mathrm{rpm}$ for $5 \mathrm{~min}$ prior to analysis using a Waters liquid chromatography coupled to quadruple time of flight mass spectrometry (LC-QtoF-MS) (Waters Corporation, Milford, USA). Samples derived from different substrates were analyzed in five replicates.

Analysis of fatty acids. BSFL samples reared on the three different substrates were snap frozen in liquid nitrogen and then ground into a fine powder and analyzed for fatty acids following the procedures described by Musundire and colleagues ${ }^{89}$. Briefly, a methyl esterification reaction was performed on $5 \mathrm{~g}$ of each sample according to procedures outlined by Christie ${ }^{91}$. A solution of sodium methoxide in methanol was prepared to generate a concentration of $15 \mathrm{mg} / \mathrm{ml}$. An aliquot of the solution $(500 \mu \mathrm{L})$ was added to each ground insect sample, vortexed for $1 \mathrm{~min}$ and then sonicated for $5 \mathrm{~min}$. The reaction mixture was incubated at $60^{\circ} \mathrm{C}$ for 1 hour, thereafter quenched by adding $100 \mu \mathrm{L}$ deionized water followed by vortexing for another $1 \mathrm{~min}$. The resulting methyl esters were extracted using GC-grade hexane (Sigma-Aldrich, St. Louis, USA) and then centrifuged at 14,000 rpm for $5 \mathrm{~min}$. The supernatant was dried over anhydrous $\mathrm{Na}_{2} \mathrm{SO}_{4}$ and then analyzed using gas chromatography coupled to mass spectrometry (GC/MS) (Agilent Technologies, CA, USA). Fatty acids were identified as their methyl esters by comparison of GC retention times and fragmentation patterns with those authentic standards and reference spectra published by library-MS databases National Institute of Standards and Technology (NIST) 05, 08 and 11. Serial dilutions of the authentic standard octadecanoic acid $(0.2-125 \mathrm{ng} / \mu \mathrm{g})$ were analyzed by GC/MS in full scan mode to generate a linear calibration curve (peak areas vs. concentration) with the following equation $\left[y=7 E+06 x-4 E+07\left(\mathrm{R}^{2}=0.9757\right)\right]$, which was used for the external quantification of the different fatty acids.

Analyses of flavonoids. BSFL samples reared on the three different substrates were analyzed for flavonoids following the procedures described by Musundire and colleagues ${ }^{89}$ The samples were separately crushed into fine powder in liquid nitrogen. Two-and-a-half (2.5) g of each sample were independently extracted in $50 \mathrm{~mL}$ methanol-water $(80: 20 \mathrm{v} / \mathrm{v})$ by ultrasonication in a sonication bath (Branson 2510, Danbury, USA) for 1 hour followed by filtration through a Whatman filter paper No. 32. The remaining residue was re-extracted twice, and the filtrate pooled separately. The extracting solvent was removed under reduced pressure at $40^{\circ} \mathrm{C}$ using a rotary evaporator (Laborata 4000, Heidolph Instrument, Germany) to give 60, 80, 100 and $120 \mathrm{mg}$ for KW, CM and SG, respectively. The extracts $(5 \mathrm{mg})$ from each of the samples were re-dissolved in $1 \mathrm{~mL}$ water-methanol $(95: 5 \mathrm{v} / \mathrm{v})$, centrifuged at 14,000 rpm for $5 \mathrm{~min}$ and the supernatant analyzed using LC-Qtof-MS (Waters Corporation, Milford, USA). Five replicates were carried out with each replicate done on a different larvae sample.

Instruments' conditions. The instrument conditions were similar to those described by Musundire and colleagues ${ }^{89}$. LC-Qtof-MS and GC-MS instruments were used in the analysis. The instrument conditions included:

LC-Qtof-MS. The chromatographic separation was achieved on a Waters ACQUITY ultra-performance liquid chromatography (UPLC) I-class system (Waters Corporation, Milford, USA). For amino acids analysis, the UPLC was fitted with an ACE C18 column $(250 \mathrm{mmx} 4.6 \mathrm{~mm}, 5 \mu$ (Aberdeen, UK) with a heater turned off and an autosampler tray cooled to $5^{\circ} \mathrm{C}$. Mobile phases of water (A) and acetonitrile (B), each containing $0.01 \%$ formic acid, was employed. The following gradients were used: $0 \mathrm{~min}, 5 \% \mathrm{~B} ; 0-3 \mathrm{~min}, 5-30 \% \mathrm{~B} ; 3-6 \mathrm{~min}, 30 \% \mathrm{~B}$; 6-7.5 min, $30-80 \%$ B; 7.5-10.5 min, $80 \%$ B; $10.5-13.0 \mathrm{~min}, 80-100 \% \mathrm{~B}, 13-18 \mathrm{~min}, 100 \% \mathrm{~B} ; 18-20 \mathrm{~min}, 100-5 \%$ $\mathrm{B}$; and $20-22 \mathrm{~min}, 5 \% \mathrm{~B}$. The flow rate was held constant at $0.7 \mathrm{ml} \mathrm{min}^{-1}$. The injection volume was $1 \mu \mathrm{L}$.

For analyses of flavonoids and aflatoxin, a UPLC was fitted to a Waters ACQUITY UPLC BEH C18 column $\left(2.1 \mathrm{~mm} \times 50 \mathrm{~mm}, 1.7 \mu \mathrm{m}\right.$ particle size; Waters Corporation, Milford, USA) heated to $40^{\circ} \mathrm{C}$ and an auto sampler tray cooled to $15^{\circ} \mathrm{C}$. Mobile phases of water (A) and methanol (B), each with $0.01 \%$ formic acid, were employed. The following gradients were used for i) flavonoids: $0-0.2 \mathrm{~min}, 10 \% \mathrm{~B} ; 0.2-3 \mathrm{~min}, 10-60 \% \mathrm{~B} ; 3-5 \mathrm{~min}, 60-80 \%$ B; 6-8 min, $80 \%$ B; $8-9$ min, $100 \%$ B; $9-10 \mathrm{~min}, 100 \%$ B; $10-10.5 \mathrm{~min} 100-10 \%$ B; and $10.5-12 \mathrm{~min} 10 \% \mathrm{~B}$; ii) aflatoxin: $0-0.2 \mathrm{~min}, 10 \% \mathrm{~B} ; 0.2-3 \mathrm{~min}, 10-90 \% \mathrm{~B} ; 3-5 \mathrm{~min}, 90 \% \mathrm{~B} ; 5-6 \mathrm{~min}, 90-10 \% \mathrm{~B}$; and $6-7 \mathrm{~min}, 10 \% \mathrm{~B}$. The flow rate was held constant at $0.4 \mathrm{ml} \mathrm{min}^{-1}$ for both analyses. 
The UPLC system was interfaced with electrospray ionization (ESI) to a Waters Xevo QToF-MS operated in full scan based on independent information acquisition $\left(\mathrm{MS}^{\mathrm{E}}\right)$ in positive mode. Data were acquired in resolution mode over the $m / z$ range $100-1,200$ for flavonoids: $m / z 100-700$ for amino acid analysis with a scan time of $1 \mathrm{~s}$ using a capillary voltage of $0.5 \mathrm{kV}$, sampling cone voltage of $40 \mathrm{~V}$, source temperature $100^{\circ} \mathrm{C}$ and desolvation temperature of $350^{\circ} \mathrm{C}$. The nitrogen desolvation flow rate was $500 \mathrm{~L} / \mathrm{h}$. For the high-energy scan function, a collision energy ramp of $25-45 \mathrm{eV}$ was applied in the T-wave collision cell using ultrahigh purity argon $(>99.999 \%)$ as the collision gas. A continuous lock spray reference compound (leucine enkephalin; $[\mathrm{M}+\mathrm{H})^{+}=556.2766$ ) was sampled at $10 \mathrm{~s}$ intervals for centroid data mass correction. The MS was calibrated across the $50-1,200 \mathrm{Da}$ mass using a $0.5 \mathrm{mM}$ sodium formate solution prepared in 90: 102 -propanol/water $(\mathrm{v} / \mathrm{v})$.

MassLynx version 4.1 SCN 712 (Waters Corporation, Milford, USA) was used for data acquisition and processing. The elemental composition was generated for every analyte. Potential assignments were calculated using mono-isotopic masses with a tolerance of $10 \mathrm{ppm}$ deviation and both odd- and even-electron states possible. The number and types of expected atoms was set as follows: carbon $<100$; hydrogen $<100$; oxygen $<50$; nitrogen $<6$; sulphur $<6^{92}$. The empirical formula generated was used to predict structures which were proposed based on the online database, fragmentation pattern, literature and confirmed using authentic standards.

Serial dilutions of authentic standards of aflatoxin $B_{1}(0.01-20 \mathrm{ng} / \mu \mathrm{l})$, rutin, quercetin, luteolin, apigenin $(1.8-181 \mathrm{ng} / \mu \mathrm{l})$, and glutamic acid $(0.01-10 \mathrm{ng} / \mu \mathrm{l})$ were also analyzed by LC-Qtof-MS in MS ${ }^{\mathrm{E}}$ mode to generate linear calibration curves (peak area vs. concentration) with the following linear equations: aflatoxin $\mathrm{B}_{1}$ $\left[\mathrm{y}=13738 x+6611.5\left(\mathrm{R}^{2}=0.9571\right)\right]$, rutin $[y=5578.4 x-39094(\mathrm{R} 2=0.9960)]$, quercetin $[y=4372.4 x+79607$ $(\mathrm{R} 2=0.9854)]$, luteolin $[y=13433 x-23256(\mathrm{R} 2=0.9994)]$ apigenin $[y=10288 x-11117(\mathrm{R} 2=0.9995)]$ and glutamic acid $[y=40137 x-1353.1(\mathrm{R} 2=0.9999)]$ which served as the basis for the external quantification of the aflatoxin, flavonoids and amino acids.

GC/MS. Fatty acid methyl esters (FAMEs) were analyzed by GC/MS on a 7890 A gas chromatograph (Agilent Technologies Inc., Santa Clara, USA) linked to a 5975 C mass selective detector (Agilent Technologies Inc., Santa Clara, USA) by using the following conditions: inlet temperature $270^{\circ} \mathrm{C}$, transfer line temperature of $280^{\circ} \mathrm{C}$, and column oven temperature programmed from 35 to $285^{\circ} \mathrm{C}$ with the initial temperature maintained for $5 \mathrm{~min}$ then $10^{\circ} \mathrm{C} \mathrm{m^{-1 }}$ to $280^{\circ} \mathrm{C}$, and held at this temperature for $20.4 \mathrm{~min}$. The GC was fitted with a HP-5 MS low bleed capillary column $(30 \mathrm{~m} \times 0.25 \mathrm{~mm}$ i.d., $0.25 \mu \mathrm{m})\left(\mathrm{J} \& \mathrm{~W}\right.$, Folsom, USA). Helium at a flow rate of $1.25 \mathrm{ml} \mathrm{min}^{-1}$ served as the carrier gas. The mass selective deceptive was maintained at ion source temperature of $230^{\circ} \mathrm{C}$ and quadrapole temperature of $180^{\circ} \mathrm{C}$. Electron impact (EI) mass spectra were obtained at the acceleration energy of $70 \mathrm{eV}$. A $1.0 \mu \mathrm{l}$ aliquot of sample was injected in the splitless mode using an auto sampler 7683 (Agilent Technologies Inc., Beijing, China). Fragment ions were analyzed over $40-550 \mathrm{~m} / \mathrm{z}$ mass range in the full scan mode. The filament delay time was set at $3.3 \mathrm{~min}$.

Statistical analysis. Statistical Analysis System (SAS, version 9.1) was used for analyses. Collected data was subjected to Levene-test to test for normality, followed by one-way analysis of variance (ANOVA) using the general linear model (GLM) procedure to test for significant differences among the means. In case of significant F-values, Bon-Tukey was used to separate the means at $\mathrm{p}<0.05$.

\section{Data Availability}

All relevant data are within the paper.

\section{References}

1. Tilman, D., Balzer, C., Hill, J. \& Befort, B. L. Global food demand and the sustainable intensification of agriculture. Proc. Natl. Acad. Sci. 108, 20260 (2011)

2. Makkar, H. P. S., Tran, G., Heuzé, V. \& Ankers, P. State-of-the-art on use of insects as animal feed. Anim. Feed Sci. Technol. 197, 1-33 (2014).

3. Alexandratos, N. \& Bruinsma, J. World Agriculture towards 2030/2050: the 2012 revision. 154 (FAO, 2012).

4. Thornton, P. K. Livestock production: recent trends, future prospects. Philos. Trans. R. Soc. B Biol. Sci. 365, 2853-2867 (2010).

5. Otte, J. et al. Livestock sector development for poverty reduction: an economic and policy perspective: livestock's many virtues. (FAO, 2012).

6. Omiti, J. M. \& Okuthe, S. O. An Overview of the Poultry Sector and Status of Highly Pathogenic Avian Influenza (HPAI) in Kenya Background Paper 117 (2008).

7. Craig, S. \& Helfrich, L. A. Understanding Fish Nutrition, Feeds, and Feeding (2009).

8. Munguti, J. M. et al. An overview of current status of Kenyan fish feed industry and feed management practices, challenges and opportunities. 128 Int. J. Fish. Aquat. Stud. 1, 128-137 (2014).

9. Akinrotimi, O., Abu, O. \& Aranyo, A. Transforming Aquaculture from Subsistence to Commercial Level for Sustainable Development in Niger Delta Region of Nigeria. J. Agric. Soc. Res. 11, 22-33 (2011).

10. Worm, B. Averting a global fisheries disaster. Proc. Natl. Acad. Sci. 113, 4895-4897 (2016).

11. Shepherd, C. J. \& Jackson, A. J. Global fishmeal and fish-oil supply: inputs, outputs and markets a: global production of fishmeal and fish-oil. J. Fish Biol. 83, 1046-1066 (2013).

12. The state of world fisheries and aquaculture 2018-Meeting the sustainable development goals. (FAO, 2018)

13. Foley, J. A. et al. Solutions for a cultivated planet. Nature 478, 337-342 (2011).

14. Tschirner, M. \& Kloas, W. Increasing the Sustainability of Aquaculture Systems: Insects as Alternative Protein Source for Fish Diets. GAIA - Ecol. Perspect. Sci. Soc. 26, 332-340 (2017).

15. Van Huis, A. \& Tomberlin, J. K. Chapter 1. The potential of insects as food and feed. In Insects as food and feed: from production to consumption. (eds Van Huis, A. \& Tomberlin, J. K.) 25-58. (Wageningen Academic Publishers).

16. Finke, M. D. \& Oonincx, D. Chapter 17 - Insects as Food for Insectivores. In In Mass Production of Beneficial Organisms. (eds Juan Morales-Ramos, M. G. R. \& Shapiro-Ilan, D.) 583-616 (San Diego: Academic Press., 2014).

17. Nowak, V., Persijn, D., Rittenschober, D. \& Charrondiere, U. R. Review of food composition data for edible insects. Food Chem. 193, 39-46 (2016).

18. Rumpold, B. A. \& Schlüter, O. K. Nutritional composition and safety aspects of edible insects. Mol. Nutr. Food Res. 57, 802-823 (2013). 
19. van Huis, A. Edible insects contributing to food security? Agric. Food Secur. 4, 20 (2015).

20. Hale, O. M. Dried Hermetia illucens larvae (Diptera: Stratiomyidae) as a feed additive for poultry. J. Ga. Entomol. Soc. 8, 16-20 (1973).

21. Stamer, A. Insect proteins-a new source for animal feed. EMBO Rep. 16, 676-680 (2015).

22. Hopley, D. The evaluation of the potential of Tenebrio molitor, Zophobas morio, Naophoeta cinerea, Blaptica dubia, Gromphardhina portentosa, Periplaneta americana, Blatta lateralis, Oxyhalao duesta and Hermetia illucens for use in poultry feeds. (Stellenbosch University, 2016).

23. Craig Sheppard, D., Larry Newton, G., Thompson, S. A. \& Savage, S. A value added manure management system using the black soldier fly. Bioresour. Technol. 50, 275-279 (1994).

24. Ramos-Elorduy, J., González, E. A., Hernández, A. R. \& Pino, J. M. Use of Tenebrio molitor (Coleoptera: Tenebrionidae) to recycle organic wastes and as feed for broiler chickens. J. Econ. Entomol. 95, 214-220 (2002).

25. van Broekhoven, S., Oonincx, D. G. A. B., van Huis, A. \& van Loon, J. J. A. Growth performance and feed conversion efficiency of three edible mealworm species (Coleoptera: Tenebrionidae) on diets composed of organic by-products. J. Insect Physiol. 73, 1-10 (2015).

26. Elwert, C., Knips, I. \& Katz, P. A novel protein source: maggot meal of the black soldier fly (Hermetia illucens) in broiler feed. Tag. Schweine- Geflügelernährung 140-42 (2010).

27. van Huis, A. Insects as Human Food. in Ethnozoology 195-213, https://doi.org/10.1016/B978-0-12-809913-1.00011-9 (Elsevier, 2018).

28. Tomberlin, J. K., Sheppard, D. C. \& Joyce, J. A. Selected Life-History Traits of Black Soldier Flies (Diptera: Stratiomyidae) Reared on Three Artificial Diets. Ann. Entomol. Soc. Am. 95, 379-386 (2002).

29. Erickson, M. C., Islam, M., Sheppard, C., Liao, J. \& Doyle, M. P. Reduction of Escherichia coli O157:H7 and Salmonella enterica Serovar Enteritidis in Chicken Manure by Larvae of the Black Soldier Fly. J. Food Prot. 67, 685-690 (2004).

30. Liu, X. et al. Dynamic changes of nutrient composition throughout the entire life cycle of black soldier fly. PLoS ONE 12, https://doi. org/10.1371/journal.pone.0182601 (2017).

31. Bhada-Tata, P. \& Hoornweg, D. A. What a waste?: a global review of solid waste management. 1-116 (The World Bank, 2012).

32. Njoroge, B., Kimani, M. \& Ndunge, D. Review of municipal solid waste management: A case study of Nairobi, Kenya. International Journal of Engineering and Science 4, 16-20 (2014).

33. Tidwell, J. H. \& Allan, G. L. Fish as food: aquaculture's contribution. EMBO Rep. 2, 958 (2001).

34. Association of Official Analytical Chemists \& Helrich, K. Official methods of analysis of the Association of Official Analytical Chemists. (The Association of Official Analytical Chemists, 1990).

35. Janssen, R. H., Vincken, J.-P., van den Broek, L. A. M., Fogliano, V. \& Lakemond, C. M. M. Nitrogen-to-Protein Conversion Factors for Three Edible Insects: Tenebrio molitor, Alphitobius diaperinus, and Hermetia illucens. J. Agric. Food Chem. 65, 2275-2278 (2017).

36. Willis, S. The use of soybean meal and full fat soybean meal by the animal feed industry. In 12th Australian soybean conference. Soy Australia, Bundaberg (2003)

37. Spranghers, T. et al. Nutritional composition of black soldier fly (Hermetia illucens) prepupae reared on different organic waste substrates: Nutritional composition of black soldier fly. J. Sci. Food Agric. 97, 2594-2600 (2017).

38. Nguyen, T. T. X., Tomberlin, J. K. \& Vanlaerhoven, S. Ability of Black Soldier Fly (Diptera: Stratiomyidae) Larvae to Recycle Food Waste. Environ. Entomol. 44, 406-410 (2015).

39. Caligiani, A. et al. Composition of black soldier fly prepupae and systematic approaches for extraction and fractionation of proteins, lipids and chitin. Food Res. Int. 105, 812-820 (2018).

40. Moghaddam, H. N., Mesgaran, M. D., Najafabadi, H. J. \& Najafabadi, R. J. Determination of Chemical Composition, Mineral Contents, and Protein Quality of Iranian Kilka Fish Meal. Int. J. Poult. Sci. 6, 354-361 (2007).

41. Newton, L et al. The black soldier fly, Hermetia illucens, as a manure management/resource recovery tool (2005).

42. St-Hilaire, S. et al. Fish Offal Recycling by the Black Soldier Fly Produces a Foodstuff High in Omega-3 Fatty Acids. J. World Aquac. Soc. 38, 309-313 (2007).

43. Crenshaw, T. Calcium, phosphorus, vitamin D, and vitamin K in swine nutrition. In Swine Nutrition (eds Lewis, A. \& Southern, L.) 187-212 (CRC Press, 2001).

44. Ewing, W. \& Charlton, S. J. Calcium. In The Minerals Directory 5a-5f, and 19a. (ontext Products Ltd, 2007).

45. Hafeez, A. et al. Implication of milling methods, thermal treatment, and particle size of feed in layers on mineral digestibility and retention of minerals in egg contents. $\mathbf{9 4}$ (2015).

46. Finke, M. D. Complete Nutrient Content of Four Species of Feeder Insects. Zoo Biol. 32, 27-36 (2013).

47. Dierenfeld, E. S. \& King, J. Digestibility and Mineral Availability of Phoenix Worms, Hermetia illucens, Ingested by Mountain Chicken Frogs, Leptodactylus fallax. J. Herpetol. Med. Surg. 18, 100-105 (2008).

48. Newton, L., Sheppard, C., Watson, D. W. \& Burtle, G. Using the black soldier fly, Hermetia illucens, as a value-added tool for the management of swine manure. Report for Mike Williams, Director of the Animal and Poultry Waste Management Center, North Carolina State University (2005).

49. Barragan-Fonseca, K. B., Dicke, M. \& van Loon, J. J. A. Nutritional value of the black soldier fly (Hermetia illucens L.) and its suitability as animal feed - a review. J. Insects Food Feed 3, 105-120 (2017).

50. Newton et al. 1977. J. Anim. Sci., 44 (3): 395-400 | Feedipedia. Available at, https://www.feedipedia.org/node/16397 (Accessed: 6th March 2019).

51. Weber, G. M. \& Windisch, W. Producing Sufficient Animal-Source Protein for the Growing World Population. In Sustainable Nutrition in a Changing World (eds Biesalski, H. K. et al.) 321-334, https://doi.org/10.1007/978-3-319-55942-1_25(Springer International Publishing, 2017).

52. Henchion, M., Hayes, M., Mullen, A. M., Fenelon, M. \& Tiwari, B. Future Protein Supply and Demand: Strategies and Factors Influencing a Sustainable Equilibrium. Foods 6 (2017)

53. Veldkamp, T. \& Bosch, G. Insects: a protein-rich feed ingredient in pig and poultry diets. Anim. Front. 5, 45-50 (2015).

54. Protein sources for the animal feed industry: expert consultation and workshop, Bangkok, 29 April - 3 May 2002; [FAO Expert Consultation and Workshop on Protein Sources for the Animal Feed Industry]. (Food and Agriculture Organization of the United Nations, 2004).

55. Nutrient Requirements of Poultry: Ninth Revised Edition, 1994, https://doi.org/10.17226/2114 (National Academies Press, 1994).

56. Arango Gutiérrez, G. P., Vergara Ruiz, R. A. \& Mejía Vélez, H. Compositional, microbiological and protein digestibility analysis of the larva meal of hermetia illuscens 1. (diptera:stratiomyiidae) at angelópolis - antioquia, colombia. Rev. Fac. Nac. Agron. Medellín 57, 2491-2500 (2004).

57. Sacks, F. M. \& Willett, W. W. More on chewing the fat. The good fat and the good cholesterol. N. Engl. J. Med. 325, 1740-1742 (1991).

58. Institute of Medicine. Dietary Reference Intakes: The Essential Guide to Nutrient Requirements, https://doi.org/10.17226/11537 (The National Academies Press, 2006).

59. Asif, M. Chemical characteristics and nutritional potentials of unsaturated fatty acids. Chem. Int. 16 (2015)

60. DeFoliart, G. R. Insects as human food. Crop Prot. 11, 395-399 (1992).

61. Akullo, J., Agea, J. G., Obaa, B. B., Acai, J. O. \& Nakimbugwe, D. Process development, sensory and nutritional evaluation of honey spread enriched with edible insects flour. Afr. J. Food Sci. 11, 30-39 (2017). 
62. Oranut, S., Subhachai, B., Shen, L. \& Li, D. Lipids and Fatty Acid Composition of Dried Edible Red and Black Ants. Agric. Sci. China 9, 1072-1077 (2010).

63. Leong, S., Kutty, S., Tan, C. \& Tey, L. Comparative Study on the Effect of Organic Waste on Lauric Acid Produced by Hermetia illucens Larvae via Bioconversion. Journal of Engineering Science and Technology, Special Issue on ACEE 2015 Conference 8, 52-63 (2015).

64. Zheng, L., Li, Q., Zhang, J. \& Yu, Z. Double the biodiesel yield: Rearing black soldier fly larvae, Hermetia illucens, on solid residual fraction of restaurant waste after grease extraction for biodiesel production. Renew. Energy 41, 75-79 (2012).

65. Berezina, N. Insects: novel source of lipids for a fan of applications. OCL 24, D402 (2017).

66. Masson, L. et al. Fatty acid composition of soybean/sunflower mix oil, fish oil and butterfat applying the AOCS Ce 1j-07 method with a modified temperature program. Grasas Aceites 66, e064 (2015).

67. Lieberman, S., Enig, M. G. \& Preuss, H. G. A Review of Monolaurin and Lauric Acid: Natural Virucidal and Bactericidal Agents. Altern. Complement. Ther. 12, 310-314 (2006).

68. Ramos, M. J., Fernández, C. M., Casas, A., Rodríguez, L. \& Pérez, A. Influence of fatty acid composition of raw materials on biodiesel properties. Bioresour. Technol. 100, 261-268 (2009).

69. Fortuoso, B. F. et al. Glycerol monolaurate in the diet of broiler chickens replacing conventional antimicrobials: Impact on health, performance and meat quality. Microb. Pathog. 129, 161-167 (2019).

70. Saeed, M. et al. Quercetin: Nutritional and beneficial effects in poultry. Worlds Poult. Sci. J. 73, 355-364 (2017).

71. Musundire, R., Zvidzai, J. C. \& Chidewe, C. Bio-Active Compounds Composition in Edible Stinkbugs Consumed in South-Eastern Districts of Zimbabwe. Int. J. Biol. 6 (2014).

72. Cheseto, X. et al. Potential of the Desert Locust Schistocerca gregaria (Orthoptera: Acrididae) as an Unconventional Source of Dietary and Therapeutic Sterols. PLOS ONE 10, e0127171 (2015)

73. Kelemu, S. et al. African edible insects for food and feed: inventory, diversity, commonalities and contribution to food security. J. Insects Food Feed 1, 103-119 (2015).

74. Kreft, S., Knapp, M. \& Kreft, I. Extraction of Rutin from Buckwheat (Fagopyrum esculentum Moench) Seeds and Determination by Capillary Electrophoresis. J. Agric. Food Chem. 47, 4649-4652 (1999).

75. Hara, Y., Luo, S. J., Wickremasinghe, R. L. \& Yamanishi, T. Special issue on tea. Food Rev. Int. 11, 371-542 (1995).

76. Stewart, A. J. et al. Occurrence of flavonols in tomatoes and tomato-based products. J. Agric. Food Chem. 48, 2663-2669 (2000).

77. Marone, P. A. Chapter 7 - Food Safety and Regulatory Concerns. In Insects as Sustainable Food Ingredients (eds Dossey, A. T., Morales-Ramos, J. A. \& Rojas, M. G.) 203-221, https://doi.org/10.1016/B978-0-12-802856-8.00007-7 (Academic Press, 2016).

78. Tola, M. \& Kebede, B. Occurrence, importance and control of mycotoxins: A review. Cogent Food Agric. 2, 1191103 (2016).

79. Purschke, B., Scheibelberger, R., Axmann, S., Adler, A. \& Jäger, H. Impact of substrate contamination with mycotoxins, heavy metals and pesticides on growth performance and composition of black soldier fly larvae (Hermetia illucens) for use in the feed and food value chain. Food Addit. Contam. Part A, https://doi.org/10.1080/19440049.2017.1299946 (2017).

80. Belluco, S. et al. Edible Insects in a Food Safety and Nutritional Perspective: A Critical Review: Insects in a food perspective.... Compr. Rev. Food Sci. Food Saf. 12, 296-313 (2013).

81. Choi, W., Yun, J., Chu, J. \& Chu, K. Antibacterial effect of extracts of $\mathrm{H}$ ermetia illucens (D iptera: $\mathrm{S}$ tratiomyidae) larvae against G ram-negative bacteria. Entomol. Res. 42, 219-226 (2012).

82. Jeon, H. et al. The Intestinal Bacterial Community in the Food Waste-Reducing Larvae of Hermetia illucens. Curr. Microbiol. 62, 1390-1399 (2011).

83. Diener, S., Zurbrügg, C. \& Tockner, K. Conversion of organic material by black soldier fly larvae: establishing optimal feeding rates. Waste Manag. Res. 27, 603-610 (2009).

84. Kroeckel, S. et al. When a turbot catches a fly: Evaluation of a pre-pupae meal of the Black Soldier Fly (Hermetia illucens) as fish meal substitute - Growth performance and chitin degradation in juvenile turbot (Psetta maxima). Aquaculture 364-365, 345-352 (2012).

85. Byrne, J. Internationally funded project behind insect feed approval push in Kenya and Uganda. feednavigator.com (2017).

86. Insects As Feed EU Legislation - Aquaculture, Poultry \& Pig Species. IPIFF Available at, http://ipiff.org/insects-eu-legislation/. (Accessed: 26th November 2018).

87. Van Soest, P. J., Robertson, J. B. \& Lewis, B. A. Methods for Dietary Fiber, Neutral Detergent Fiber, and Nonstarch Polysaccharides in Relation to Animal Nutrition. J. Dairy Sci. 74, 3583-3597 (1991).

88. Hamilton, M. L. et al. Elucidation of the biosynthesis of the di-C-glycosylflavone isoschaftoside, an allelopathic component from Desmodium spp. that inhibits Striga spp. development. Phytochemistry 84, 169-176 (2012).

89. Musundire, R., Osuga, I. M., Cheseto, X., Irungu, J. \& Torto, B. Aflatoxin Contamination Detected in Nutrient and Anti-Oxidant Rich Edible Stink Bug Stored in Recycled Grain Containers. PLoS ONE 11, https://doi.org/10.1371/journal.pone.0145914 (2016).

90. Cheng, Y. \& Cappozzo, J. Sensitive Femtogram determination of aflatoxins B1, B2, G1 and G2 in food matrices using Triple Quadrapole LC/MS. Chromatogr Today 3-4 (2008).

91. Christie, W. W. Preparation of Ester Derivatives of Fatty Acids for Chromatographic. Analysis. Adv. Lipid Methodol. 2, 69-111 (1993).

92. Jared, J. J., Murungi, L. K., Wesonga, J. \& Torto, B. Steroidal glycoalkaloids: chemical defence of edible African nightshades against the tomato red spider mite, Tetranychus evansi (Acari: Tetranychidae). Pest Manag. Sci. 72, 828-836 (2016).

\section{Acknowledgements}

This research was financially supported by the Canadian International Development Research Centre (IDRC) and the Australian Centre for International Agricultural Research (ACIAR) (INSFEED - Cultivate Grant No: 107839001), German Ministry for Economic Cooperation and Development (BMZ) through the Deutsche Gesellschaft für Internationale Zusammenarbeit (GIZ) \& ENTONUTRI - 81194993, WOTRO Science for Global Development (NWO-WOTRO) (ILIPA - W 08.250.202), through the International Centre of Insect Physiology and Ecology (icipe). We also gratefully acknowledge the icipe core funding provided by UK Aid from the Government of the United Kingdom; Swedish International Development Cooperation Agency (Sida); the Swiss Agency for Development and Cooperation (SDC); Federal Ministry for Economic Cooperation and Development (BMZ), Germany, and the Kenyan Government. The funders had no role in study design, data collection and analysis, decision to publish, or preparation of the manuscript. The authors are extremely thankful to their esteemed colleague Dr. Guido Luechters (ZEF) for his valuable assistance in the data analysis, to Professor Baldwyn Torto for allowing use of icipe's Behavioral and Chemical Ecology Unit's laboratory and facilities, to Mr. Erick Ngalla, Isaiah E Rachami and Mr. Dennis Muthoni (icipe) for their technical assistance.

\section{Author Contributions}

M.S., I.M.O., F.M.K., C.M.T., K.K.M.F., S.S., S.E. and C.B. conceived the experiment, M.S. conducted the experiments, M.S. and I.M.O., analyzed the results. All authors reviewed the manuscript. 


\section{Additional Information}

Competing Interests: The authors declare no competing interests.

Publisher's note: Springer Nature remains neutral with regard to jurisdictional claims in published maps and institutional affiliations.

(c) (i) Open Access This article is licensed under a Creative Commons Attribution 4.0 International License, which permits use, sharing, adaptation, distribution and reproduction in any medium or format, as long as you give appropriate credit to the original author(s) and the source, provide a link to the Creative Commons license, and indicate if changes were made. The images or other third party material in this article are included in the article's Creative Commons license, unless indicated otherwise in a credit line to the material. If material is not included in the article's Creative Commons license and your intended use is not permitted by statutory regulation or exceeds the permitted use, you will need to obtain permission directly from the copyright holder. To view a copy of this license, visit http://creativecommons.org/licenses/by/4.0/.

(c) The Author(s) 2019 